\title{
Digital Twins Driven Supply Chain Visibility within Logistics: A New Paradigm for Future Logistics
}

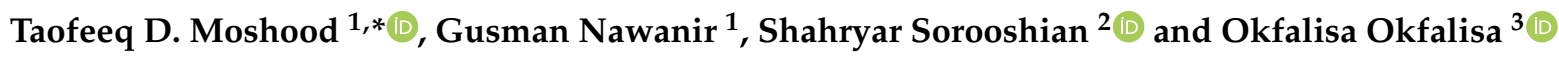 \\ 1 Faculty of Industrial Management, Universiti Malaysia Pahang, Gambang Pahang 26300, Malaysia; \\ gusman@ump.edu.my \\ 2 Department of Business Administration, University of Gothenburg, 40530 Gothenburg, Sweden; \\ shahryar.sorooshian@gu.se \\ 3 Department of Informatics Engineering, Universitas Islam Negeri Sultan Syarif Kasim, Riau 28293, Indonesia; \\ okfalisa@uin-suska.ac.id \\ * Correspondence: PPO20002@stdmail.ump.my or taofeeqmoshood@gmail.com
}

\section{check for}

updates

Citation: Moshood, T.D.; Nawanir, G.; Sorooshian, S.; Okfalisa, O. Digital Twins Driven Supply Chain Visibility within Logistics: A New Paradigm for Future Logistics. Appl. Syst. Innov. 2021, 4, 29. https://doi.org/10.3390/ asi4020029

Received: 18 March 2021

Accepted: 16 April 2021

Published: 21 April 2021

Publisher's Note: MDPI stays neutral with regard to jurisdictional claims in published maps and institutional affiliations.

Copyright: (c) 2021 by the authors. Licensee MDPI, Basel, Switzerland. This article is an open access article distributed under the terms and conditions of the Creative Commons Attribution (CC BY) license (https:// creativecommons.org/licenses/by/ $4.0 /)$.

\begin{abstract}
The supply chains shaping their distribution networks become more diverse as companies respond to global markets' stringent criteria. This is also counterproductive to the visibility of the supply chain within the company and can adversely affect the organization's core business. This paper attempts to evaluate how organizations can benefit from introducing Digital Twins to enhance their logistics supply network visibility. Additionally, deployment issues and technologies supporting Digital Twins were reviewed. This study used ATLAS.ti 9 software tools to save, classify, and evaluate the data for this analysis to systematically review the literature. We reviewed, compiled, and sorted papers from 227 publications for this article and then recognized 104 as critical to the work scope; this analysis' quest date was set from 2002 to 2021. This article represents the first attempt at dealing with the issue of supply chain visibility through the Digital Twins in the logistics field. The research outcomes found that Digital Twins would help companies develop predictive metrics, diagnostics, projections, and physical asset descriptions for their logistics. This study also suggested some steps to overcome the challenges in implementing a Digital Twins in the logistics industry. For researchers, this review offers the possibility to unify and expand existing solutions and to identify links and interfaces that are still needed. As for managerial implications, this study can be used to identify future strategies and technologies to fulfil certain logistics tasks and develop new technological solutions for current and future demands.
\end{abstract}

Keywords: logistics; digital twins; industry 4.0; supply chain visibility; cloud computing; internet of things; manufacturing

\section{Introduction}

The cornerstone of an organization is a working logistics supply chain. Organizations whose core industries are based on internal and external logistics development play a crucial role in ensuring that the organization's core business will continue without halting [1]. However, it is essential to outline the central purpose of logistics quite briefly, transporting everything from point $X$ to $Y$. Based on the particular mission at hand, the methods of doing so may differ considerably. These activities are becoming more challenging for many companies as global economies impose higher consumer customization expectations. The items produced and the manufacturing lines themselves entail more complex technologies. It is becoming increasingly challenging to identify alternatives to the core businesses' technical problems [2,3]. The method of obtaining information about the supply chain's internal workings is becoming more complicated as distribution supply chains grow more dynamic. Any company in which the supply chain has a critical function can quickly become a concern since lacklustre accountability and exposure of the supply chain can throw clouds on outdated processes that may otherwise be rectified [4,5]. Ensuring maximum control of 
the supply chain not only grants access to a variety of evidence that can act as a foundation for business choices. It also offers greater capacity to adapt rapidly to developments and make fast operating decisions in real-time based on changes in demand or production [6,7].

Although the supply chain's visibility is necessary, achieving and retaining full visibility through a supply chain network spanning the globe is a challenge bordering on the impossible without using recent digital technology developments [8,9]. The automotive business and culture as a whole are on the edge of what is sometimes referred to as "Industry $4.0^{\prime \prime}$ or the fourth industrial revolution $[7,10]$. Rapid advancement and integration to emerging technology innovations and mindsets are the core aspects of Industry 4.0. Many new technologies increasingly find further adoption and different uses within our current industrial framework [11,12]. The approaches and ideas in the context of "Industry 4.0" are situated at the interface of the disciplines of electrical engineering, business administration, computer science, business and information systems engineering, mechanical engineering, and the participating segments. The illustrated parts of Industry 4.0 result in general fields of activity, which are of particular interest for business and information systems engineering. The increasing digitalization of all manufacturing and manufacturing-supporting tools results in registering a growing amount of actor and sensor data, supporting functions of control and analysis [13]. Digital processes evolve due to the likewise increased networking of technical components. In conjunction with the increase in the digitalization of produced goods and services, they lead to completely digitalized environments [10,14]. Those are, in turn, driving forces for new technologies such as simulation, digital protection or virtual resp. Many of the innovations that make up the fourth industrial revolution are gradually utilizing innovative development, big data analytics algorithms, and sophisticated humanmachine interfaces, to name only a few [15]. Four main categories can be roughly grouped into these different technologies [16]: (1) Cyber-physical constructs. (2) Platforms for the Internet of Things (IoT). (3) Computing cognitively. (4). Cloud computing.

A fascinating field of technical research within the industrial framework of Industry 4.0 is that of Digital Twins [17]. A Digital Twins is a form of cyber-physical device that uses numerous IoT sensors and produces a high-fidelity visual image of a physical asset. The abundance of data obtained by the Digital Twins is then aggregated and analyzed using machine learning algorithms to promote strategic and organizational decision-making [18]. As organizations adapt to global markets' rigorous demands, the supply chains that constitute their logistics networks become increasingly complex. This often has a detrimental effect on the organization's supply chain visibility, which may negatively impact the organization's core business. This article aims to determine how organizations can improve their logistical supply chain visibility by implementing a Digital Twins-an all-encompassing virtual representation of the physical assets that constitute the logistics system.

Furthermore, challenges related to implementation and the necessary steps to overcome these challenges were examined. This article will discuss possible Digital Twins applications in a logistical environment, particularly when it comes to enhancing the visibility of a complicated supply chain in the distribution network. Our research aims to consider the advantages and obstacles contributing to introducing Digital Twins in logistics.

The remainder of this article is formulated in the following way. Section 2 develops the research materials and methods, and Section 3 discusses the supply chain's visibility. The literature is analyzed in Section 4 to establish the impact of Digital Twins upon supply chain visibility. Section 5 describes Digital Twins, and Section 6 describes the technologies enabling Digital Twins; Sections 7 and 8 illustrate the benefits of a Digital Twins and the challenges when implementing a Digital Twins. The findings are stated in Section 9 and some discussion and management implications in conjunction with the results. Finally, in addition to recommending more research directions, Section 10 discusses the study's conclusion. 


\section{Research Materials and Methods}

In order to jointly explore supply chain visibility and Digital Twins, the literature review phase promotes the control of different knowledge pools, such as scholarly inquiries set out in this study. Traditionally, the narrative aspect of management study evaluations has brought together many shortcomings, including prejudice and lack of objective judgment [19]. Systematic assessments encourage the development of sound information bases, provide analytical rigour for fundamental study issues by straightforward and thorough scanning of literature, objective examination, and mapping of "unknowns" and "knowns" in the fields of investigation [20]. As a consequence of such evaluations, knowledge obtained helps to inspire prospective thinking and strategy structures in the examined organizational development areas [21,22]. This paper applies the systematic analysis process centered on the evidence in the management review literature to maintain a concentrated, transparent and reproducible assessment of empirical investigations with a high degree of credibility owing to the reduced likelihood of inclusion of biases [6,7].

We adopted the recommendations given by Tranfield et al. [19], Rousseau et al. [23], Watson [24], and Durach et al. [25] for this systematic literature review to: (1) identify current publications, (2) pick and measure their findings, (3) evaluate and synthesize the evidence, (4) comment on the outcomes, and (5) suggest a strategic plan. The specific steps of a detailed and comprehensive systematic review are being used as follows: the study questions were proposed in stage 1 ; the appropriate literature materials were identified and reviewed in stage 2; the recovered studies were filtered, analysed, and validated for inclusion in the analysis in compliance with the established requirements and research goals in stage 3; related knowledge and evidence were collected from the materials and descriptive and thematic analysis of the results in stage 4; The outcomes, disseminating core concepts, potential directions and an evolving avenue of integration study exploration in stage 5 were reported $[20,26,27]$.

\subsection{Search and Selection Process}

Via the usage of aggregator databases like Scopus (https:/ /www.scopus.com/search/ form.uri?display=basic\#basic, accessd on 19 April 2021) and publishing databases like Elsevier (https:/ / www.sciencedirect.com/, accessd on 19 April 2021), Taylor \& Francis ( https: / /www.tandfonline.com/, accessd on 19 April 2021), MDPI (https:/ / www.mdpi. $\mathrm{com} /$, accessd on 19 April 2021), and Google Scholar, articles within the framework of the research have been found and extracted. Logistics, Digital Twins, Industry 4.0, Supply chain visibility, Cloud Computing, Internet of Things, and Manufacturing were the prevalent keywords at the same time. While the usage of this level of granularity of the database (aggregator and publisher level) resulted in a certain degree of correlation between the two domain tiers, this offered confirmation of the aggregate searches performed to collect all applicable material in the literature [27]. Only peer-reviewed journal articles and conference proceedings were included in the analysis to ensure the academic fields' inclusion under the scrutiny of the most credible materials and publications of exceptional managerial effect [28]. They contained only articles written in the English language.

The Kyoto Protocol's adoption in 2002 was recognized as a remarkable achievement in global supply chain activities and global sustainability logistics, with the bulk of sustainability integration research in line with the research objective of this analysis adopting this global initiative [29]. The first search results can be obtained using the publications in conference papers, articles, and books, but later omitted excluding articles. Consequently, after initial refinement, 227 papers persisted as articles. Finally, 132 documents were picked for the purpose of the review paper after eliminating duplicates.

Centered on these main achievements in the fields of efficiency, global sustainability of logistics, supply chain visibility, and Digital Twins publication, the quest date for this analysis was set from 2002 to 2021. The research in between 1990-2001 periods was searched to confirm this position. This search did not, however, find materials necessary to this review's study concerns. 


\subsection{Literature Consideration}

To save, identify, and interpret this research proof, the ATLAS.ti Version 9 package is suitable. One benefit of using ATLAS.ti Version 9 was that for keywords, patterns, relationship charts, and other analysis features, easy access to quotations is possible. Using the ATLAS.ti Version 9, the auto-code innovation has initially been used for the primary stage of analysis to identify and mark as quotations all areas of the knowledge institution where ATLAS.ti Version 9 was implemented. These quotations were grouped for appraisal into a separate register, and the quotes were regularly analysed in connection with the method of study. All papers were read repeatedly and clarified, driven by the research subject, to identify recurrent trends and ideas $[30,31]$. To achieve three kinds of reports, the collected materials were planned. (1) Overall report: the papers obtained are initially explained by their research backgrounds to describe the literature assessment's overall intent. (2) Detailed description: This study's primary focus is on supply chain visibility and Digital Twins. Five primary word forms discussed above distribute the obtained posts [32]. The relevant items shall control a comprehensive report on the products obtained, such as the testing goals, strategies, and productivities, the significance of supply chain visibility, and Digital Twins (i.e., advancement in the supply chain, sustainable logistics implementation, individual perspectives, customer satisfaction, service quality, imitations tools and examination components). (3) Lastly, an interaction review which is a further argument on Digital Twins is driven supply chain visibility within logistics research for integrated design through multiple papers that were carried out. Furthermore, a discussion on other possibilities, such as difficulty adopting Digital Twins-driven supply chain visibility within the logistics sector, and their benefit was explained below [33].

\subsection{Analysis Process}

The approach outlined in this manuscript shows one possible way of applying qualitative research to text results. In the preparation and exploration of supply chain visibility and Digital Twins in ATLAS.ti Version 9, various separate stages are described. Each stage of the evaluation phase is then organized around the sections of Processes, Findings, and Discussion, allowing the reader to further understand how the data are evaluated and follow the process' implications and the resulting data. The papers identified were screened, filtered, and validated for inclusion in the analysis via an iterative selection method after the outlined systematic literature review procedure, as seen in Figure 1.

Duplicates have been excluded as part of this process, eligibility has been verified from abstracts, and the complete content of outstanding papers has been checked in the context of the study issues for the final judgment regarding the supply chain visibility and Digital Twins areas under examination [34]. As per the systematic literature review protocol for this study, the 104 papers were screened and verified as valid. 


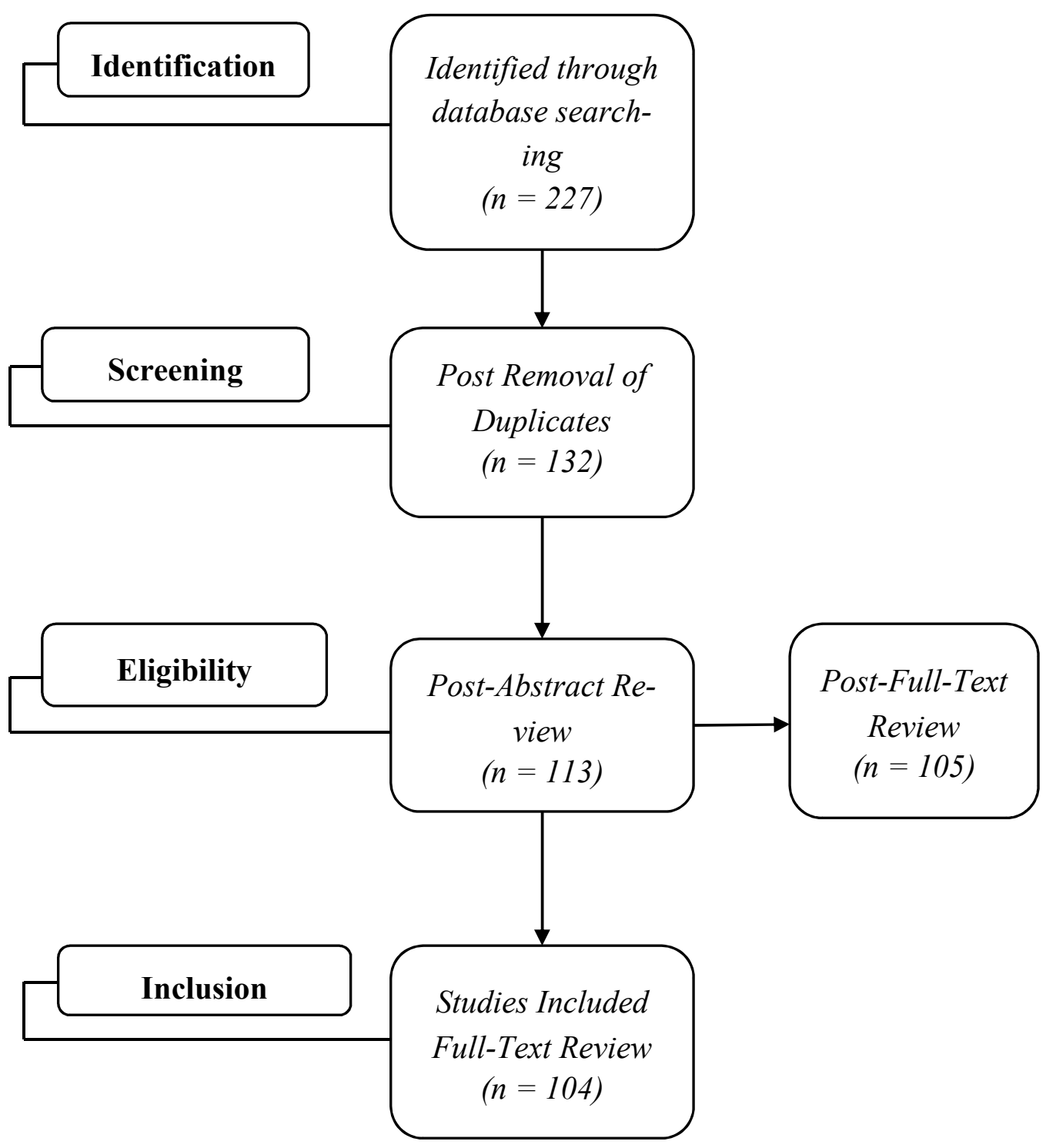

Figure 1. Overview of paper identification, selection, and inclusion process.

\subsection{Analysis Using ATLAS.ti Version 9}

This section conserves the organization of the technique section-each phase of the research process is addressed. To save, identify, and interpret this research evidence, the ATLAS.ti Version 9 package is suitable. For the research review, it requires five components: Purpose: This research aims to provide insight into the modern production and ultimate potential of supply chain visibility and Digital Twins; Concentration: This article discusses supply chain visibility and Digital Twins research features (i.e., goals, strategies, sustainability, outputs); Viewpoint: This analysis provides a neutral view on the study of articles; Design: This article is ordered by conceptual order first, then connected; Coverage: The literature coverage is extensive [33].

For someone unfamiliar with the software, the use of ATLAS.ti Version 9 (quotation, families, and network) jargon would certainly mean nothing. In contrast, Weisheng Lu and Yuan [35] used machine terms and explained them to enable readers to consider what was happening. The researchers identified the methodological approach, software, and version in this description and what features were used for the analysis (quotes, codes, and system hierarchy with memos). The sense of quotes has been clearly expressed, and the relationship between quotes and codes [30]. The researcher briefly explained how the software was used, which may help inform people unfamiliar with qualitative data analysis 
software. One benefit of using the ATLAS.ti Version 9 was keywords, topics, relationship charts, and other analysis features, as easy access to quotations as possible. In ATLAS.ti Version 9, Figure 2 provides word cloud knowledge that helps novices understand how an understanding of software is allowed. In ATLAS.ti Version 9 applications, Figures 3 and 4 represent a network view that demonstrates how the data codes are related to the two major themes arising from the logistical supply chain visibility by implementing Digital Twins strategies. In this case, the authors suggested that the data was generated using the network function of ATLAS.ti Version 9.

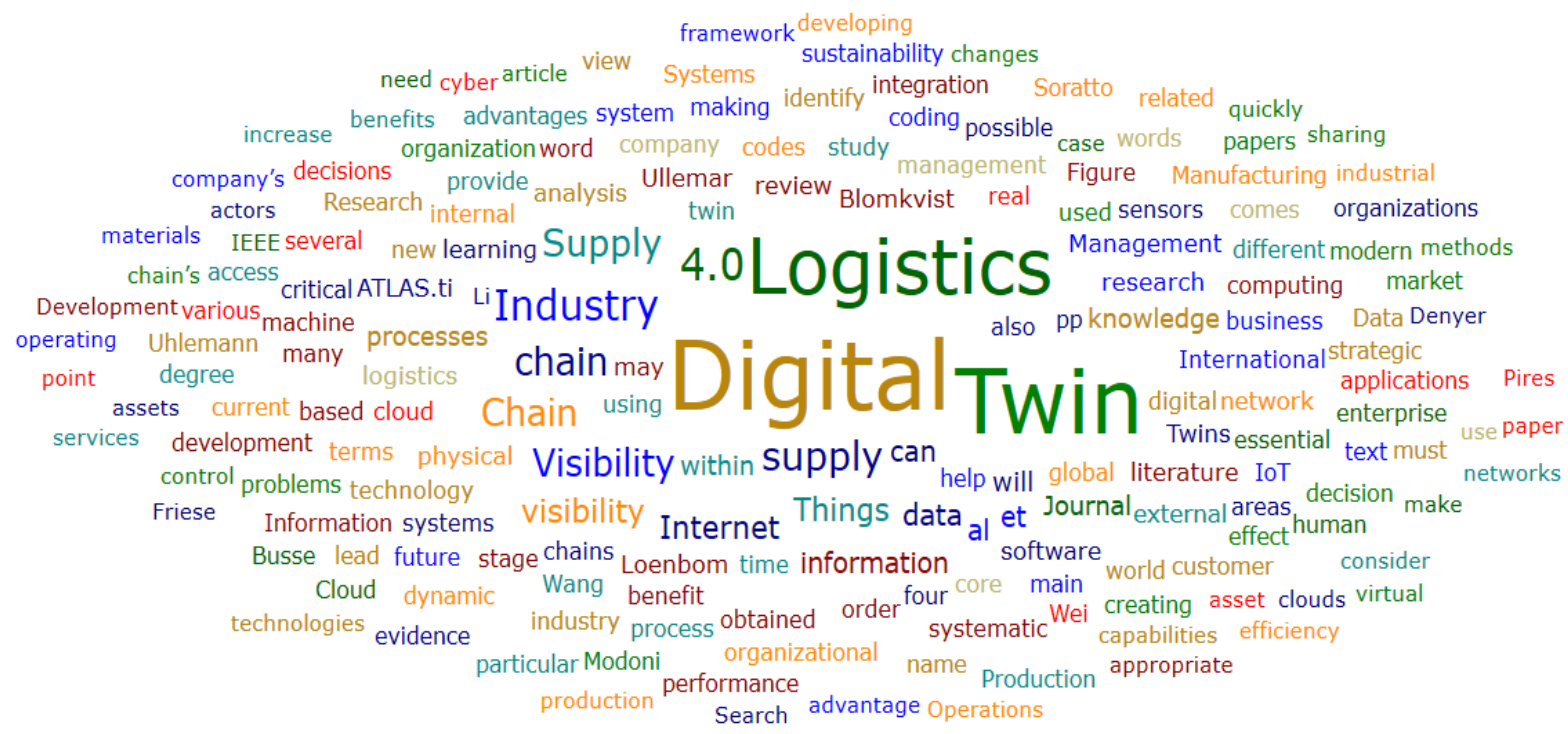

Figure 2. Word cloud information on Digital Twins is driven supply chain visibility within logistics.

Word cloud: Running the Word cloud and creating ATLAS.ti Version 9 software knowledge helps novices learn how to view applications. Word clouds have become very common when viewing textual content, where a keyword's font size might reflect its frequency in the text. There are many methods for the organization of words [36]. Word Cloud is an easy and intuitive visualization tool that is often used to provide a first impression of text documents. Usually, the most common words in a text are displayed as a weighted list of words in a particular spatial structure (e.g., sequential, circle, random). The words' font sizes indicate their significance or frequency of occurrence for graphical purposes or visually encode additional information.

On the other hand, (e.g., colour, position, orientation) are also varied. For more indepth text analyses, word clouds can serve as a starting stage. However, accessible word cloud visualizations offer very little assistance in comparing various text documents' terms and word frequencies [36]. To overcome this restriction, we used ATLAS.ti Version 9, an extended word cloud visualization that systematically merges and displays the words from several text documents. It provides an outline of the papers and allows clearly apparent variations and commonalities in word usage. The required information for the word cloud is shown in Figure 2.

Basically, the ATLAS.ti Version 9 comprises a series of smaller word clouds that define numerous document combinations. The word clouds are organized with those reflecting the outer circle's individual documents and the inner circles' combined ones in a centered sequence. The cloud concept contains the words inside the innermost circle that exist in all documents. The background colour saturation, which increases with the degree of aggregation, reinforces this composition principle. The word cloud (Figure 2) is explained in detail in this article. We describe the visualization theory and its application after summarizing the related work. 


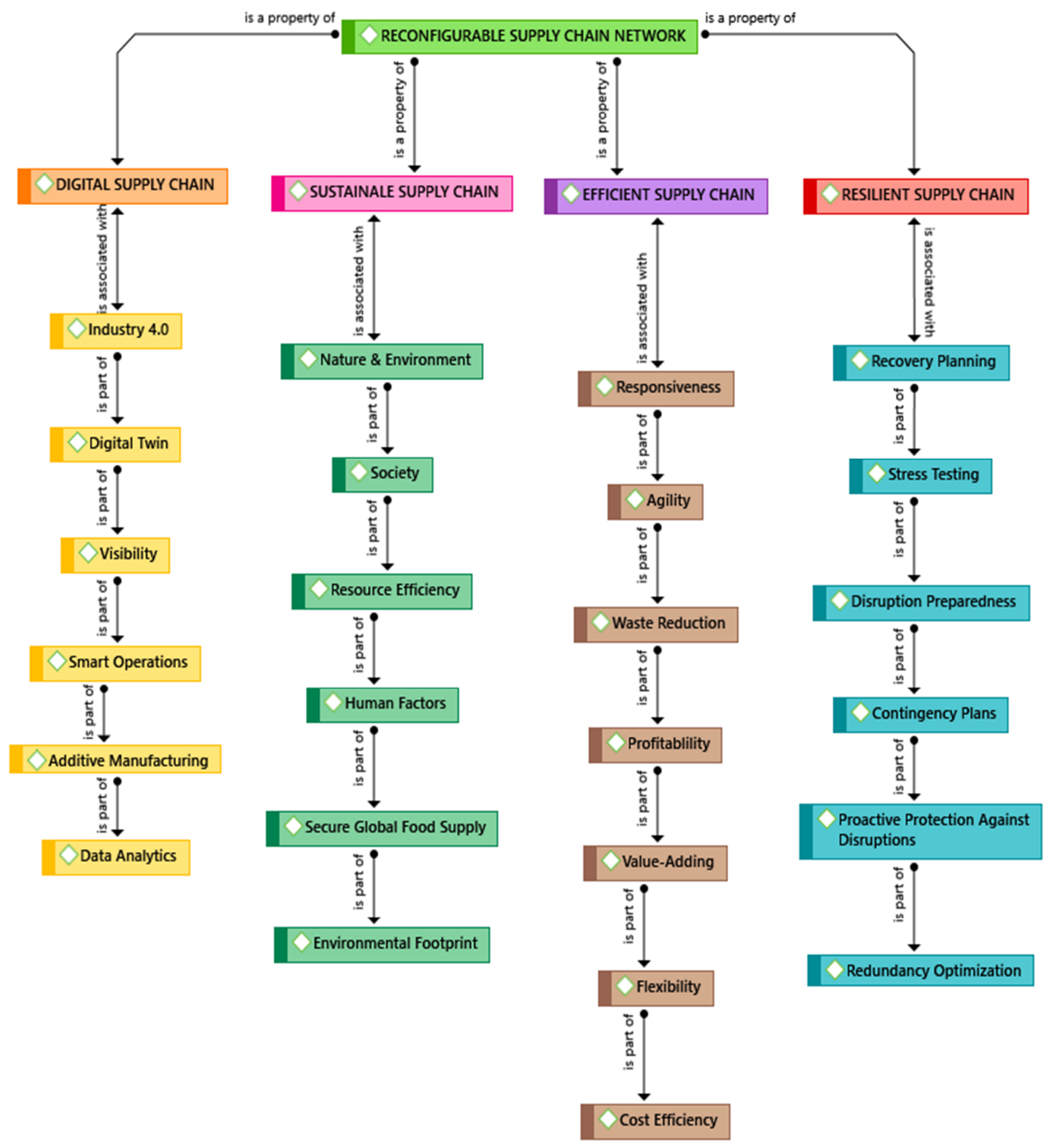

Figure 3. Atlas.ti network view on reconfigurable supply chain network. 


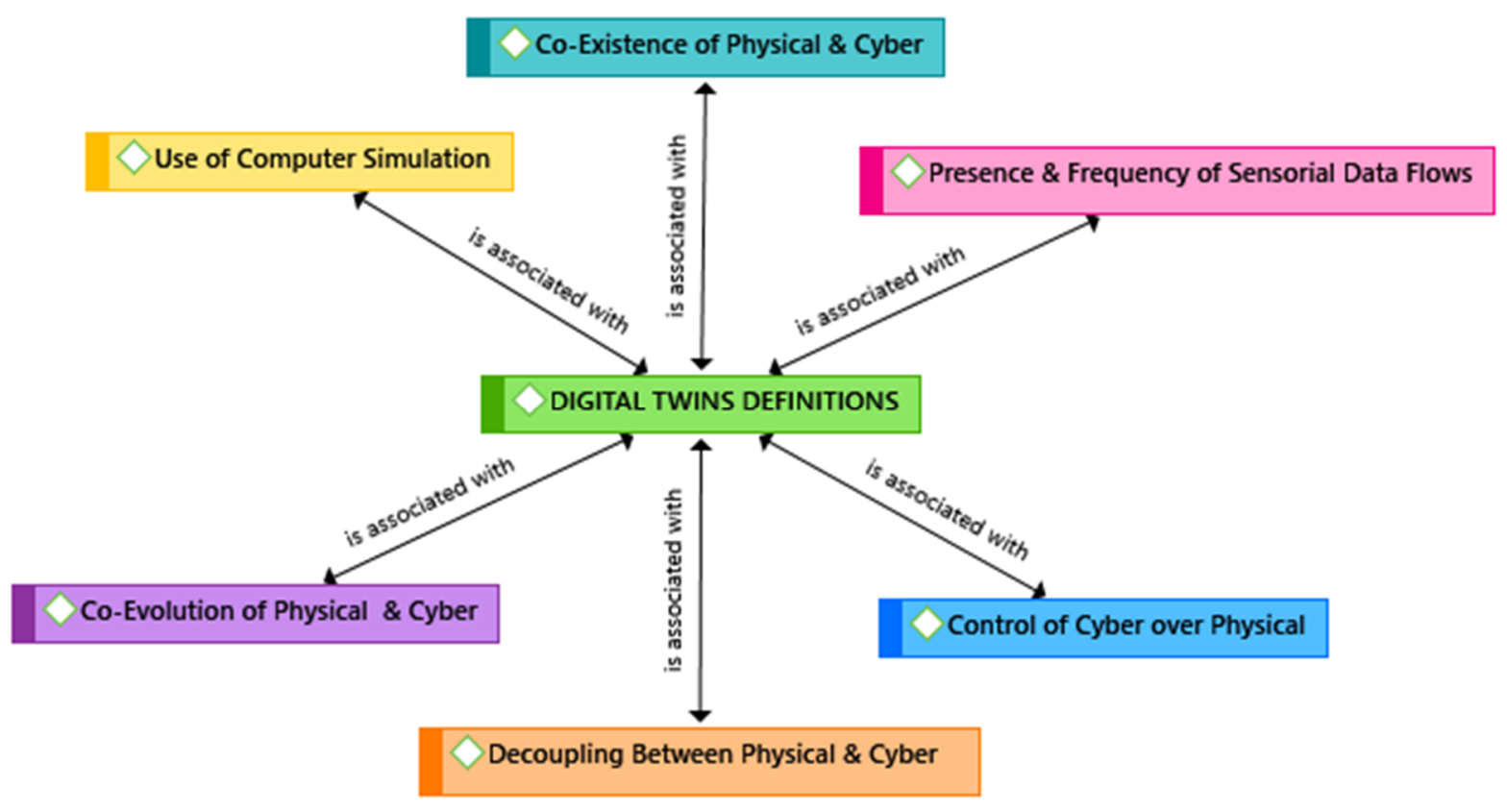

Figure 4. Atlas.ti network view on Digital Twins definitions.

Open coding: Upon initial analysis of text results, the researcher will recognize several words, sentences, and other words of interest related to this article or field of interest with the open coding feature of the ATLAS.ti Version 9 package. A "quotation" is labelled with Open Coding and uses the same wording to produce a message from the same passage. It is not uncommon to come to a point where we will have more than a couple of pages of codes as we begin developing codes with fresh ideas [36]. At that point, to find the correlations and classify them into classes based on their common properties, we may research the codes. We may also consider the codes' dimensions that reflect the property's position within a continuum or set. The name of the category can vary from the codes to help communicate its width, and, if appropriate, we may even create sub-categories from the codes and then apply them to the categories [37]. Open coding is usually the initial stage of qualitative data analysis. We may do gravitational coding and selective coding after finishing open coding, depending on the technique we use. At the later stage of the study, such coding enables one to create models in an inductive process. The required information for mathematics is shown in Figures 3 and 4.

Data Analysis: The principal investigator had a clear overview of the data after designing the coding frame. It optimized the codes used to interpret and re-read the data several times. Concerning the research issue, the next step was to group codes into a coherent pattern. It is like creating a plotline where a portion of the plot is made up of the theme. Thirty-five code groups were formed to review the case study data and further summarize them into two subject areas that serve as the first ideas for themes (see Figures 3 and 4). Figures 3 and 4 illustrate how the codes surrounding work-related problems were further discussed in the theme creation process. The network feature ATLAS.ti Version 9 was used for this. Codes that all contributed to the supply chain visibility, logistics, and Digital Twins were drawn into a network and connected to each other. This is not an automatic method [37]. The software creates no connections or names the links. The software only provides the researcher with space for conceptual thought. This occurs as the networks arrange the nodes, think of meaningful connections, and name those connections. For instance, the keyword research, together with the interface visualization and network [38], brings us to four principles essential to the macro-framework of reconfigurable supply chain network by presenting a critical reading of the recent literature from a supply chain and Digital Twins point of view: sustainability, digitalization, leagility, and resilience, as shown in Figure 3. 
Some recurrent themes concerning core organizational facets of a Digital Twins are outlined in Figure 4. The degree to which Digital Twins and physical objects are coupled is probably the most popular of these themes. It is not always clear, in particular, which aspects of the real structure should be considered under review and to what degree of abstraction. Digital Twins perception as mirror image shows that all facets of a factory's output properties must be captured [39]. If accomplished, such a Digital Twins will not be distinct from what it tries to mirror and will thus be of no benefit to investigate and think from it. Likewise, terms such as real-time can mean no lag in cyber-physical updates with no need to sample sensor data. Considering the prevalence of cyber over physical, closely related problems emerge around the Digital Twins principle: if the former produces and communicates the latter's findings or acts on it [40]. Simultaneously, terms such as co-evolution suggest any physical effect on cyber, as the latter supposedly redefines its own boundaries as both go along. Digital Twins can be of minimal value in exploring alternate designs and scenarios if physical and cyber co-existence is presumed. Computer simulations tend to play a significant role in the conceptualization of a Digital Twins, although there is no consensus on Digital Twins modelling [41], especially in the sense of supply chains [39].

\section{Supply Chain Visibility}

The supply chain's visibility is part of the larger supply chain management area. A philosophy focused on developing visibility across supply chains to facilitate internal decision-making and operational efficiency. In recent years, supply chain visibility research has been squarely established in the academic limelight. Global megatrends towards globalization have raised several challenges in handling organizations' current supply chains as they grow in line with consumer demands [6,42]. At its core, the supply chain visibility depends on ensuring that the organization provides access to reliable and current knowledge concerning the supply chains in terms of internal and external processes [43,44]. This is done by determining which supply chain operations are most significantly impacted by a lack of clarity and developing methods of gathering and exchanging appropriate data between all parties involved [6,45]. Ensuring adequate visibility in a company's supply chain will have several beneficial consequences by optimizing predicting, preparation, arranging, and order implementation, to name a few $[46,47]$. With the latest technologies in the industry, such as Digital Twins, Artificial intelligence (AI), Internet of things (IoT), and Robotic Process Automation (RPA), more automation is now possible for managing end-toend supply chain operations. Figure 5 shows supply chain visibility and control tower.

Visibility necessitates a cross-divisional platform that helps in proactively managing end-to-end supply chains in real-time. A high degree of visibility is only possible when the core elements-people, technology, and process-work in tandem. Although visibility is strongly related to information sharing, it is crucial to distinguish the two since information sharing is an operation. In contrast, visibility is a likely outcome of information sharing practices [49-51]. The key advantages of exposure in the supply chain are the general increase in market efficiency, offering a foundation for better decision-making, both at strategic and organizational levels [52,53]. Organizations benefit from proper visibility of the supply chain at a functional level by having the capacity to reconfigure the supply chain rapidly and effectively [54]. An ability that is becoming extremely relevant in quickly changing market conditions creates a competitive advantage. In their 2010 paper, Wei and Wang suggest that four main visibility processes enable an enterprise to reorganize its supply chain in compliance with both its own requirements and external demands $[46,47]$. These are visibility for learning, visibility for sensing, visibility for integrating, and visibility for coordinating [44]. 


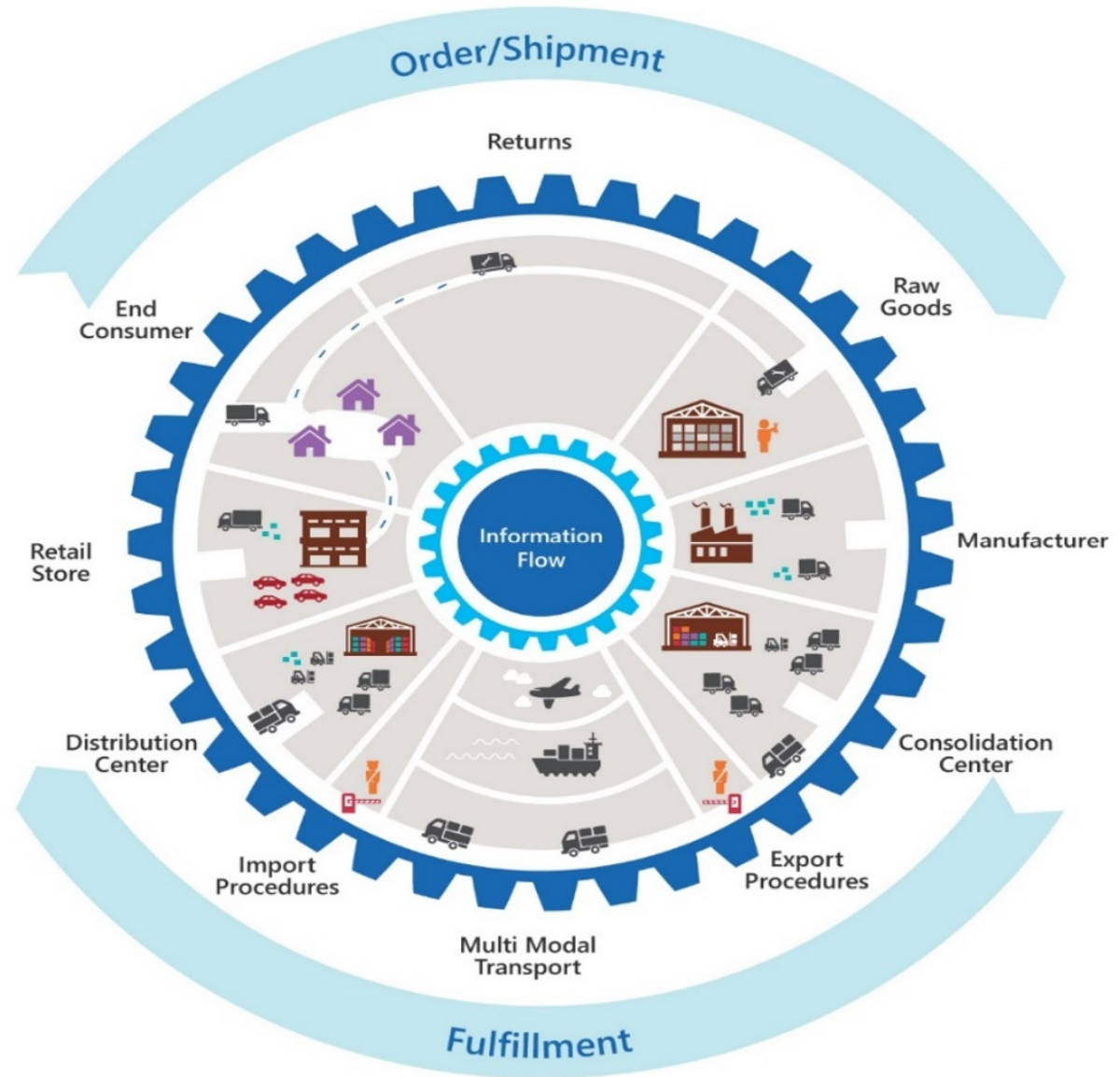

Figure 5. Supply Chain Visibility and Control Tower. Source: Reprinted with permission from [48].

\subsection{Visibility for Learning}

This shows how new knowledge and information from internal and external processes can be obtained and absorbed by the enterprise. Knowledge of external processes impacting the enterprise is essential to sustaining business advantage, and companies may gain additional knowledge and expertise from their supply chain partners [55]. The importance of active learning processes within an enterprise directed at suppliers and customers should not be overlooked because the process of assessing and responding to external processes is a critical element in the identification and development of new market opportunities [7]. Bringing additional information into one's enterprise from various external channels may lead to insights interlinking with new concepts, further increasing the desired processes' efficiency. According to Zollo and Winter [56], three key processes underpin the dynamic learning process: acquisition of information (the very process of acquiring knowledge), articulation of knowledge (outlining the knowledge so that it can be transmitted with others), and codification of knowledge (adopting the experience acquired and applying the knowledge to one's organization). Adopting dynamic learning mechanics within an organization will further benefit from promoting a culture of insight and quality development, facilitating systems within the organization through which workers raise their ideas that may be useful for their job areas [46,47].

\subsection{Visibility for Coordinating}

This illustrates how experienced the company is at coordinating multiple aspects of the supply chain, making decisions about several different actors within the system with overarching repercussions. It is essential to provide complete supply chain knowledge for ensuring a higher degree of decision-making on business decisions that influence the supply chain since global commodity flows are the sum of a multitude of different 
stakeholders [57]. According to Kraft, Valdés, and Zheng [58], coordination is the practice of controlling logistics, which processes rely on each other, which mechanisms there need to be to move items, and which devices are required make the supply chain completely usable. To provide clarity for collaboration, the emphasis should be on supplying information to handle the various forms of dependencies within the supply chain between the various actors [59]. To ensure proper visibility for collaboration, the exchange of information between participants within the supply chain is essential: sharing real-time details of when and where goods are to be distributed, establishing consistent instructions on appropriate inventory levels and buffer supplies and order and demand predictions, to name only a few [7]. Additionally, exchanging awareness about the finished product's desired features is helpful, as distributors can then receive and operate on information about product specifications and consumer wishes [60].

\subsection{Visibility for Sensing}

This measure illustrates how rapidly the enterprise can collect real-time information on internal and external operations and adapt to an evolving market climate [61]. Existing business analytics on customer demands is one of the most critical items of supply chain information. As the importance of market and customer information, information cannot be understated to create opportunities from changes in the business environment $[46,47]$. Organizations with solid information-sharing systems in place with business partners and stakeholders within their supply chain can reap a multitude of advantages, being able to respond quickly to changes in consumer tastes and demands and acting quickly on new business opportunities that may have been left unaware of by competitors without information-sharing systems in place [7].

\subsection{Visibility for Integrating}

This illustrates how adaptable the company is when it comes to implementing and incorporating emerging strategies and technology to establish a competitive market advantage [62]. According to the supply chain, forming a collective culture is a crucial phase in supply chain management. It allows a mentality that enables the alignment of processes within the supply chain between various stakeholders [46,47]. To achieve this, knowledge must be exchanged amongst the different players on all the main processes within the supply chain since knowing others' central processes will lead to breakthroughs in developing the supply chain as a whole. Long-term partnerships with high levels of knowledge exchange between business partners have been found to appear to show greater visibility in terms of incorporation [57,63]. It is beneficial for the company as a whole to consider the strengths, benefits, and difficulties of the other players in the supply chain when it comes to maintaining harmony between the various actors and providing a strong common objective to work for [7].

Maintaining sufficient control of the supply chain within an enterprise by integrating processes that improve these four indicators above will contribute to a substantial improvement of strategic and operational knowledge in real-time, which in turn can lead to a drastic impact on reducing the volatility of production, also known as the bullwhip effect, that has the added benefits of lower complexity within the company and improved consumer satisfaction [7]. The adoption and integration of modern technologies to obtain, manage and analyse information are primary factors behind increased visibility in the supply chain. As such, as mentioned above, information technology such as Digital Twins is expected to profoundly benefit all four main facets of the supply chain's visibility [46,47].

\section{Digital Twins}

Michael Grieves first proposed the idea of Digital Twins at a University of Michigan presentation on Product Lifecycle Management in 2003 [64]. NASA created the first actionable Digital Twins in 2011 as a way to forecast aircraft structural performance by examining and designed to simulate them as virtual objects. NASA scientists later described 
Digital Twins as "an interactive multiphysics, multiscale, probabilistic simulation of a vehicle or device that uses the highest quality physical models, sensor update fleet history, and so on, to mirror the life of its flying twin [65]. A Digital Twins is a unique, virtual representation of a physical thing that monitors and simulates both the physical state and behavior of the thing [17]. The digital copy is continually connected to the physical object(s) and updates itself to reflect real-world changes. Applied to products, machines and even entire business ecosystems, Digital Twins can reveal insights from the past, optimize the present and even predict future performance [65].

The report explains the concept and rise of Digital Twins and how it creates value [66]. The technology, which involves using digital models to better understand and manage physical assets, is already well established in some industries and has the potential to change logistics operations [18] significantly. For a graphic representation, see Figure 6.

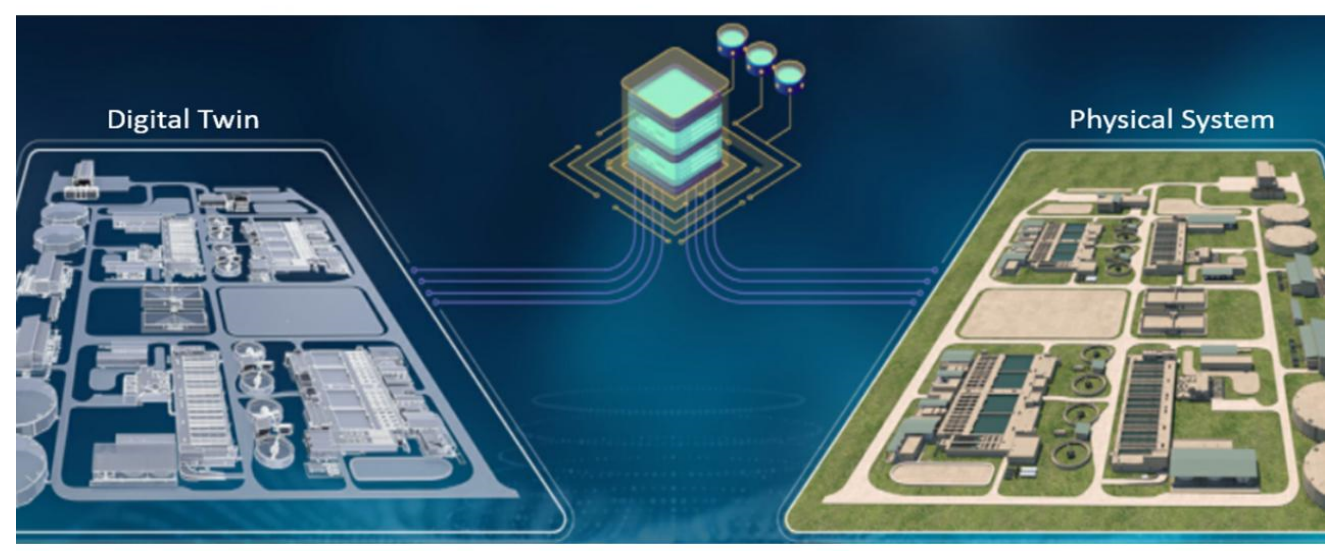

Figure 6. Visual Representation of Digital Twins. Source: Reprinted with permission from [67].

Suppose the number of possible Digital Twins implementations increases by the day. In that case, it becomes evident that there is no existing consensus in the scientific world on what constitutes a typical Digital Twins. It may entice an organization to enthusiastically mark its current 3D-modeling systems that include asset-tracking technology as a Digital Twins. This strategy avoids diluting and underselling the complexity and future advantages of a fully-fledged Digital Twins [18]. The following list of features is a suggested description of what makes a Digital Twins interested in furthering the consensus and acting as a foundation for future scholarly endeavours. These features are based on the personal study as well as findings from scholarly works by Qi et al. [66], Lu et al. [65], Uhlemann et al. [17], and Negri et al. [18]. The below are the characteristics:

- A Digital Twins is a virtual representation (or model) of a physical object or process.

- The Digital Twins is continuously updated with real-time data to reflect the physical object or process's current state and behavior.

- The Digital Twins can help visualize and analyse the physical object or process, and by use of machine learning, further optimizations and predictions can be made.

These characteristics can be used to widely cover any possible Digital Twins implementations, from something as small as a portion of a manufacturing line to something as big as the entire city.

\section{Improving Supply Chain Visibility with a Digital Twins}

\subsection{The Impact of Digital Twins upon Supply Chain Visibility}

In order to increase the visibility of the supply chain, it soon becomes evident that providing functioning Digital Twins integrated within a company's logistical supply chain will prove very useful [68]. Many scholars point out that the advent of modern digital technology positively impacts the supply chain's visibility, especially those that allow for an overview of previous challenges to detect processes within the supply chain. Digital 
Twins are no exception to this [7,69]. It will possibly help boost all four organizational visibility factors discussed in the theoretical structure section by providing a functioning Digital Twins. In particular, a Digital Twins will dramatically improve the metrics of visibility for sensing (quickly gathering knowledge about internal and external processes) and visibility for learning (how quickly the information gathered can be processed), and this aggregated network of information can then be used to organize internal and external processes better. That said, introducing a Digital Twins is a dynamic and resource-intensive matter, and putting a Digital Twins in place does not always assure perfect visibility of the supply chain.

\subsection{Visibility for Sensing and the Digital Twins}

As described in the theoretical context, there are four separate areas to explore when looking at what a Digital Twins might do to increase the supply chain's visibility. Visibility for sensing is the first type, reflecting the degree to which the enterprise can easily acquire real-time knowledge about internal and external processes and adapt to an evolving market climate. For an organization, the introduction of a Digital Twins will be tremendously helpful in this respect. The Digital Twins sensors could obtain new data types, offering more insight into the supply chain flows [70]. The Digital Twins will then identify realtime changes and alert the company about them by aggregating and interpreting the sensors' data. Therefore, as more sensors are introduced and incorporated, the supply chain's exposure will also begin to improve [71]. Naturally, to ensure data consistency that will cause the Digital Twins to draw assumptions that correctly mirror the fact, one must carefully consider the sensor versions. The company must also ensure that sufficient sensors are mounted for each given flow or scenario to allow the most productive use of the data obtained [7].

When it comes to optimizing supply chain visibility for internal sensing, a Digital Twins will help the company recognize improvements in demand in their supply flows more quickly [72]. With the introduction of Digital Twins to content preparation, the company will provide a more precise understanding of how many items should be ordered, resulting in a visible improvement in sensing exposure when it comes to enhancing supply chain visibility for external sensing. Using a Digital Twins in material preparation would help packaging planning gain greater visibility because packaging could be ordered alongside Digital Twins material orders [73]. This, combined with a Digital Twins that tracks packaging during the packaging period, will allow the company to be more responsive to shifts in demand for packaging. A Digital Twins may also expose the gaps in the packaging cycle, providing the packaging purchasing department with a real-time and precise picture of how demand for packaging improves [74].

\subsection{Visibility to Learning and the Digital Twins}

According to theory, Visibility for learning implies the extent to which new information and knowledge from both internal and external mechanisms can be obtained and absorbed by the institution. The theory notes that understanding external systems is essential for business advantage and that partners will bring new business knowledge to organizations [75]. Thus, a Digital Twins that maintains track of transport may be a potential learning opportunity to learn more about the way transport suppliers operate. In order to strengthen the supply chain for all sides, openness with commodity manufacturers may also lead to understanding more about the inner workings of their operations and whether organizations can do more [76]. However, since greater disclosure runs the risk of exposing confidential information to allies or rivals, the Digital Twins is carefully supervised and who has access to it is crucial.

Another example of how a Digital Twins can impart knowledge in increasing learning visibility is in the packaging industry [76]. As previously mentioned, having a clearer understanding of the right approaches for product repair and care can result in longer packaging lifetimes, and monitoring and tracing will assist in visualising where the black 
holes are in the packaging cycle. Dynamic learning involves three types of mechanisms: experience accumulation (the act of accumulating knowledge), knowledge articulation (the act of describing knowledge such that it can be communicated with others), and knowledge codification (adopting the experiences garnered and adapting the knowledge to the organization) [77]. The knowledge gathered by the Digital Twins may assist in finding the cause of an emerging issue in terms of experience accumulation. When it comes to suggesting solutions for a crisis, understanding the root cause can be incredibly helpful. When working with Digital Twins, it is also important to care about knowledge articulation. If the Digital Twins discovers new concepts, it is important to make sure that this learning is available and well-articulated for the environment to which it relates [78]. For example, once the root cause of the black hole in the packaging loop is uncovered, all of the players concerned must be made aware of this information to prepare and respond. It is important to standardise communication and ensure that relevant consumers access the material. The Digital Twins architecture must be structured to be flexible in terms of information codification [79]. If knowledge is discovered using the Twin, the company will need to make systemic or organizational improvements. In any case, the Digital Twins must be able to respond to these changes.

\subsection{Visibility for Coordinating and the Digital Twins}

The supply chain visibility paradigm notes that teamwork visibility shows how effective the company is at managing various aspects of its supply chain. It is essential to provide full knowledge when it comes to ensuring a higher degree of decision-making on strategic decisions that influence the supply chain. In having such results, a Digital Twins may be of great benefit [80]. For example, if a Digital Twins could better forecast or interpret the need for products or materials, it could guide financial and budgeting decision-making. Besides, a Digital Twins may help keep track of individual packaging, enabling strategic decision-making within the packaging period regarding the amount of packaging in motion [7].

Since Digital Twins can help create credible models of logistical movements, they may be a valuable tool for enhancing supply chain visibility for organizing. For example, a full Digital Twins might simulate the reorganization of logistical flows [81]. This would not only help calculate the future benefit achieved from introducing a different series of logistical flows, but it would also help predict vulnerabilities that would otherwise go unnoticed [82]. However, since a completely integrated Digital Twins is a long-term approach that does not happen immediately, it will be a long time before a company can use it as a modelling tool.

\subsection{Visibility for Integrating and the Digital Twins}

In order to build a strategic advantage, the theoretical paradigm decrees that visibility for integration reflects how adaptable the company is when it comes to implementing and incorporating new approaches and technology. Besides, establishing a typical supply chain identity is a critical step in terms of supply chain management as it allows a mentality that promotes the alignment of processes within the supply chain between actors [75]. Knowledge of critical processes must be exchanged between different actors to help with this, as knowing others' core processes can lead to developments that can strengthen the supply chain. To assist with this, a Digital Twins can act as a valuable weapon, as it allows obtaining an analysis of vital internal processes within the respective supply chains. To recap the above discussion, Digital Twins are expected to have a significant effect in terms of increasing the visibility of the supply chain, as other digital solutions have been seen to be highly helpful in improving the visibility of the supply chain within organizations [83]. However, there are many problems to consider, all of which rely on maintaining technical data accuracy while still reducing and decreasing the amount of human error. The global megatrends in digital transformation and autonomous processes are expected to have enormous synergy implications concerning Digital Twins and supply chain management. 
It would be critical for all companies who seek to increase their visibility in the supply chain to stay updated on these developments [74].

\section{The Technologies Enabling Digital Twins}

\subsection{Machine Learning}

One of the quickest developing scientific areas today is machine learning. It incorporates components from both computer science and statistics and can be represented as a computer system that automatically enhances its efficiency over experience [84]. The terms artificial intelligence (AI) and machine learning are also used synonymously. Machine learning, though, is considered a subset of $\mathrm{AI}$, which is a wider concept that covers the entire artificial intelligence area. Therefore, while machine learning is the same as AI, machine learning is not exactly the same as AI [85]. There is a wide range of implementations in which speech recognition, computer vision, language processing, and robot control are used for machine learning, just to name a few. It may be more useful for certain machine learning programs to teach the algorithm by giving it example inputs and outputs instead of manually coding it. Machine learning is now being applied progressively in several sectors, including health care, education, engineering, marketing, customer service, and logistics [84].

\subsection{Internet of Things}

The Internet of Things refers to all objects, often fitted with pervasive knowledge, that are connected to a network. A wide distribution network of communicative devices is generated by combining many objects for interaction through embedded systems, enabling contact between human devices and devices [86]. New standards of visibility and adaptability could be allowed to implement IoT, and efficiency could be increased in different fields, from smart homes to supply chains. In a supply chain, data obtained from various sensors in different locations could be processed and eventually informed by early alerts to human operators about any possible issues [87]. They must be fitted with sensors for IoT devices to provide any relevant data to communicate with each other. The IoT sensors come in all shapes and sizes. They are vitally important for the Digital Twins idea as they provide the knowledge with which a Digital Twins can analyse and assess the actual state of its physical twin [88].

\subsection{Cloud Computing}

Cloud computing is a paradigm for allowing access to computing services from a public network. The customer may access a pool of services that are owned and managed by a third party through the internet through cloud computing. Access to these properties is different from their physical location. Data storage, databases, computational capacity, and services like data analytics processing are examples of computing capabilities used in cloud computing [89]. The benefit of using a cloud is that there is no need for the customer to purchase and own costly hardware or own any computing space. The customer only pays for the cloud services they need, with the option to scale up or scale down their desired services at all times. Cloud services have three significant models: Information as a Service (IaaS), Platform as a Service (PaaS), and Software as a Service (SaaS). While cloud computing is now a common technology, it has been debated in terms of protection in some situations. The cloud also has a variety of clients using the same $[7,88]$.

\subsection{Augmented and Virtual Reality}

In terms of increasing user experience, both augmented and virtual reality are becoming increasingly popular tools. Virtual reality is a technology that emulates the real world by creating a virtual world and how the user virtually experiences it [90]. This virtual world could be anything from creating a real-world high-fidelity figment to the simulation of a particular portion of the user experience. In contrast, augmented reality, rather than creating a whole new virtual world, adds a layer of information to the real 
world [91]. Some smartphone applications use a tangible example of everyday augmented reality, where elements are clearly visible through the phone camera that cannot be seen in the physical world [92]. In a Digital Twins context, both augmented and virtual reality can be useful tools to view and inspect the Digital Twins either on a screen (2D) or in a physical space (3D). The aforementioned technologies such as IoT, cloud computing, APIs and machine learning all provide and process the necessary data and infrastructure to create and visualize a Digital Twins in either augmented or virtual reality $[93,94]$.

\subsection{Application Programming Interface}

Application Programming Interfaces allow applications such as databases, networks, and IoT sensors to interact. APIs are building blocks that are designed to be recycled by developers, so one does not have to redo the programming from scratch. A simple example of this is the Google Maps API, which can be easily combined with third-party content to view local points of interest on a Google Map. The third party would not have to schedule a completely new map in this scenario, which saves both time and money [95]. APIs help to transfer data easily from clouds, computers, and other systems, as many modern enterprises deal with cloud computing [7].

\section{The Benefits of a Digital Twins}

As Digital Twins applications' complexity and scope will differ widely, the possible advantages are similarly numerous. A Digital Twins helps the customer remotely perform their twin properties' regular activities, maximizing and reducing service costs. Digital Twins can also be used to automate monotonous activities that may often be prone to human error-something which subsequently allows resources to be centred around more value-adding activities [7]. Early adopters of Digital Twins often see value being added in three distinct categories: improved decision-making thanks to higher quality data, optimization of day-to-day processes, and freeing up resources which enables integration of new business models [7,17]. For instance, a Digital Twin can enable a shift towards servitization and product-as-a-service within companies that previously had no option whatsoever to do so, as managing an asset through its lifecycle becomes increasingly streamlined by the use of a Digital Twin. As illustrated below, the list of benefits can be further grouped into four main groups.

\subsection{Analytical Value}

The ability to capture data that is typically difficult to calculate, such as information produced from an asset's interior, is another advantage of using Digital Twins. Using this information, decisions and recommendations can then be taken to maximize future generations of assets $[7,63]$.

\subsection{Descriptive Value}

Data of the twinned physical asset will automatically be viewed from a distance by using Digital Twins. Although there are many advantageous uses for this remote surveillance form, it may be especially desirable if the physical assets are situated in unsafe areas [7]. Remote visualization using Digital Twins can also be incredibly beneficial in collecting data for assets working beyond regular day-to-day activities, long-distance transportation, remote sensor data collection, and remote observation of assets operated by a company operating in off-site manufacturing facilities, to name a few possible applications $[7,63]$.

\subsection{Predictive Value}

The prospect of making measured forecasts is an environment where Digital Twins will prove to be highly helpful. The possible future status of the physical asset can be anticipated by using the vast volume of data accumulated by the Digital Twins [7]. While impressive in and of itself, the most advanced forms of Digital Twins can not only predict the problems that will emerge, and they can also propose a solution [17]. Digital Twins 
will probably be essential when it comes to promoting future systems that will be able to make autonomous decisions about which assets to create (and when to create them) to maximize the value created for both personnel and stakeholders, Digital Twins will probably be essential [93].

\subsection{Diagnostics Value}

Digital Twins can include systems that can recommend probable underlying causes of the physical asset's present state based on the collected data. The use of advanced analytics and machine learning algorithms focused on prior quantifiable data will take the form of these diagnostic systems $[7,17]$.

\section{Challenges When Implementing a Digital Twins}

It is clear that there are several obstacles associated with the successful adoption of Digital Twins, despite the field of research only being fairly new. The following list of problems that are likely to be faced while attempting to introduce a Digital Twins has been established based on the concerns posed by $[17,96,97]$.

\subsection{Education}

In an organization, technical changes inevitably lead to workers needing to embrace and adapt to modern operating ways. This ultimately leads to problems concerning management change and knowledge transfer. It is not enough that Digital Twins owners and consumers have the requisite resources and expertise to run and manage the Digital Twins [96]. They will need to be inspired to change their attitude and operating practices, which in turn includes a detailed comprehension of the causes and motives for the change [98]. To reap all the Digital Twins' technological advantages, it also becomes obvious that the revolution in technologies would have to be combined with a change in the company's structure and working processes [17].

\subsection{Accurate Representation}

Given the current state of technology, it is challenging to develop a Digital Twins that can serve as a perfect copy of its physical asset, particularly as the artefacts and processes being twinned become more and more complicated [96]. This ultimately leads to the Digital Twins developers needing to make decisions and simplify procedures in the underlying model. Financial and technological limitations have to be matched with Digital Twins ${ }^{\prime}$ conceptual and organizational requirements [7].

\subsection{Data Quality}

It can be critical to guarantee reliable data quality in a Digital Twins application that relies on data provided by hundreds (or thousands) of IoT sensors [96]. Difficult operating conditions and communication over distant networks mean that organizations will have to build ways to identify and eliminate unreliable information and deal with inconsistencies in the information gathered [17].

\subsection{Costs}

A steep initial investment carries with it the implementation of a Digital Twins. It can be expensive to invest in any new technology platform. Considering the number of processes involved in creating and maintaining a Digital Twins, the costs can rapidly skyrocket [97]. While many of these costs are prone to drop in the future due to technological advances, the decision to introduce a Digital Twins must be carefully weighed against other solutions that could provide a fraction of the cost with similar advantages. The best solution may not be an all-encompassing Digital Twins, but instead a contained system of sensors and databases if there are only a handful of critical parameters of interest to the organization [96]. It is impossible to provide a generic response on how to keep costs low for a Digital Twins to be introduced. The volume of data to be stored and how to store 
it are enormously cost-effective considerations for operations. It is crucial to minimize development costs at a development stage to assert which data is essential to capture and how much data to process. Suppose there is constant economic pressure on the volume of data produced by the Digital Twins.

\subsection{IP Protection}

Data needs to be exchanged between several separate instances to optimize the advantages of the Digital Twins. Suppose the data being collected is directly connected to the company's core competencies. In that case, it is likely to include extremely confidential data, which poses data ownership concerns, identity assurance procedures, and user access control [96].

\subsection{Digital Security}

The amount of information that Digital Twins holds makes them useful targets for criminal interference. A hacked Digital Twins may have dangerous real-world implications, aside from the ever-present possibility of data manipulation. The Digital Twins still has the power to monitor the physical assets [12] actively. While maintaining appropriate data protection routines for networks of this magnitude can be a daunting prospect for many firms, the threats involved in ensuring the Digital Twins security are often of the utmost importance [7].

\subsection{Interoperability}

As many organizations may lack the requisite expertise to build in-house Digital Twins, organizations pursuing Digital Twins solutions risk depending entirely on simulation and AI technology supplied by external actors [17]. When enterprises become more dependent on their Digital Twins, it will prove challenging to get the same capabilities from other suppliers, causing firms to rely on external players in the long run [7].

\section{Discussion}

In order to increase the visibility of the supply chain, it soon becomes obvious that providing functional Digital Twins integrated within a company's logistical supply chain will prove very useful. Many scholars point out that the advent of modern digital technology positively impacts the supply chain's visibility, specifically ones that permit the design of an overview of processes within the supply chain that were earlier problematic to observe [72]. Digital Twins are no exception to this. It will possibly help boost all four organizational visibility factors described in the theoretical structure section by providing functional Digital Twins. In particular, a Digital Twins will significantly boost the metrics of visibility for sensing (quickly gathering knowledge about internal and external processes) and visibility for learning (how much faster the information obtained can be processed), and this aggregated net of information will be used to organize internal and external processes better and further enhance the visibility for coordination [17]. By offering a critical reading of the existing literature from a supply chain and Digital Twins viewpoint, this paper further adds to the Digital Twins supply chain debate. Possible characteristics of a Digital Twins supply chain are drawn from the exploratory industry cases based on emerging technology offered by modern industrial technology and industrial digitalization. Within and even beyond those strictly connected with particular technological interventions, possibilities and obstacles associated with each case are discussed [99]. Overall, in prior literature, the Digital Twins supply chain's conceptualization is inchoate; the possible benefits associated with it are unclear or ill-defined, and its precise implementations are scarce. The opposite view, perhaps predictably, is held by major computing tool vendors. In this article, we begin the task of identifying the main characteristics of a Digital Twins supply chain that will educate future work about its ability and how it might move beyond the visualization and analytical capabilities provided by current frameworks for supply chain system design and simulation. 


\section{Suggestions Steps to Overcome the Aforementioned Challenges in Implementing a Digital Twins}

The steps that a logistics company should take to resolve the difficulties of adopting a Digital Twins are outlined in detail in the section entitled "A Roadmap for the Development of a Digital Twins in Logistics." There are stages: (1) Framework—Plan the Digital Twins data and information system to ensure potential modularity and usability. (2) Data sourcesMeasure the availability of data and how to attain the essential data not yet available. (3) Prioritize-identify the places where the Digital Twins can continue to be applied. Start tiny and apply it on a restricted scale initially. (4) Integrate-Confirm that the present digital infrastructure can be incorporated into the Digital Twins to make appropriate current resources practice. (5) Collect data-Evaluate which sensors are needed for the Digital Twins to function and whether the ability to integrate, use, and retain this technology exists within the establishment. (6) Test-Test the partial Digital Twins to measure whether it achieves the project scope and identifies possible Twin problems. (7) Revise-Make the required changes and modifications to the partial Digital Twins. Document lessons learned during the execution that could be used for the future. (8) Repeat-Build additional partial Digital Twins in another logistics region by pursuing steps 1-7. (9) Expand-Increase the Digital Twins by linking the partial Digital Twins into an entity. (10) Follow up-Follow-up, sustain and update the Digital Twins as needed.

Based on the research and empirical evidence, the recommendation here is to start small with the Digital Twins, applying it with a limited scope and scale. One should be aware that limiting the Digital Twins scope will also restrict the outputted results, as it will not have access to all of the data from other departments [100]. The first version of the Digital Twins should be viewed as an opportunity to learn about the technology and how to apply it to the organization. Suppose this initial version of the Digital Twins needs to be completely redeveloped for any future iterations. In that case, it is necessary to view it as valuable lessons for future iterations of the Twin [101]. It is important to remember that Digital Twins applied to logistics is a very new area of research. The implementation of any such Digital Twins is akin to the act of pioneering. Further research is certain to be considered within this area, and keeping informed of any new developments is recommended.

Besides, logistics chains handle huge data flows—supply balances, carrier distribution dates, and all other related details required for logistics to work effectively add up to massive quantities of data. To ensure that the Digital Twins has the correct capabilities, the organization must first determine what kind of data is inserted into Twin. Many problems arise along the way: will data be retrieved from current databases, or must new ones be built to access other data types? Since there are multiple data collection approaches through the different systems that make up a Digital Twins, it is important to determine whether there are data repositories that are inaccessible today that could be available in the future by new technology [81].

It is important to map out Digital Twins architecture to be as easy and modular as possible. The ultimate aim is to extend and develop the Digital Twins reach in the future. Digital Twins knowledge must also be transparent and delivered intuitively. This is true for Digital Twins overall interface system as well. Although the Digital Twins system can be advanced, consumers must still grasp how to use it [83]. If managing the Digital Twins takes significant education or special skills, the Twin's planned users will be unable to use it, allowing the Digital Twins to lose significance for the enterprise rapidly. Furthermore, the user code can have several protection measures to discourage users from making errors that might jeopardise the Twin's functionality or performance [102].

Device incorporation must be handled with caution to ensure that it can continue for a long time. Building a Digital Twins that depends on data from current programmes and systems can lead to problems later on, when unreliable sub-programs can, in the worst-case scenario, cause the Digital Twins to become unreliable as well. It is vital to ensure that the current systems' viability and operability is merged into the Digital Twins [103]. 
Additionally, after the Digital Twins is completely operational, some maintenance and follow-up would almost certainly be expected. To start, the Digital Twins functionality must be continually tested. Furthermore, the Digital Twins operating parameters may be affected if some region within the organization undergoes a major transition, such as digitalization or significant organizational structure changes. The strategic objective of management should be to constantly assess which facets of the Digital Twins may enhance its potential [104]. Checkpoints for evaluating the Digital Twins output should be used during the deployment phase. These figures will also be applied to existing figures to see how much time and effort have been saved and how much money has been saved since the rollout. Decision-makers could use these case studies of successful Digital Twins applications as a starting point for further adoption within the organization.

\section{Conclusions}

It is evident from the findings of the literature review that the logistical supply chains of firms will significantly benefit from introducing a Digital Twins. As previously expanded on, though, it can be expensive and time-consuming to introduce and manage Digital Twins. Since there is little literature on the logistics of Digital Twins, it should be noted that there is enough space for future research on seeking the best methods and metrics of the scope suggested in this paper to introduce Digital Twins. Within this domain, this results in a substantial amount of unexplored areas. One of them may be to determine better how, in multiple case studies, Digital Twins can be applied to the logistics sector. This would lead to studies that could later be used to uncover further discrepancies in Logistics and product production between Digital Twins. It is important to note that it is vital that organizations interested in adopting Digital Twins must ensure a sufficient technological and digital maturity level before committing to a full-scale Digital Twins implementation. However, while Digital Twins will likely remain a long-term strategic development goal for many organizations, it is beneficial to build the digital infrastructure with a future Digital Twins in mind, facilitating future implementation.

Author Contributions: Conceptualization, T.D.M.; writing-original draft preparation, T.D.M., G.N.; writing-review and editing, S.S.; writing-review; O.O. All authors have read and agreed to the published version of the manuscript.

Funding: We would like to acknowledge the Ministry of Higher Education of Malaysia for funding this research through the Transdisciplinary Research Grant Scheme (TRGS) No. RDU191801-5.

Conflicts of Interest: The authors declare no conflict of interest.

\section{References}

1. Qadir, I.; Ali, A. Importance of logistics processes for customer service and firm performance: Evidence from furniture industry of pakistan. Manag. Sustain. Bus. Manag. Solutions Emerg. Econ. 2017, 22, 27-36. [CrossRef]

2. Mira, M.; Choong, Y.; Thim, C. Mediating role of port supply chain integration between involvement of human resource practices and port performance in Kingdom of Saudi Arabia. Uncertain Supply Chain Manag. 2019, 7, 507-516. [CrossRef]

3. Kovacs, G.; Kot, S. New logistics and production trends as the effect of global economy changes. Pol. J. Manag. Stud. 2016, 14, 115-126. [CrossRef]

4. Creazza, A.; Dallari, F.; Melacini, M. Evaluating logistics network configurations for a global supply chain. Supply Chain Manag. Int. J. 2010, 15, 154-164. [CrossRef]

5. Murciego, Á.L.; Jiménez-Bravo, D.; Martínez, D.P.; Román, A.V.; Lazo, G.L. Voice assistant and route optimization system for logistics companies in depopulated rural areas. Sustainability 2020, 12, 5377. [CrossRef]

6. Caridi, M.; Moretto, A.; Perego, A.; Tumino, A. The benefits of supply chain visibility: A value assessment model. Int. J. Prod. Econ. 2014, 151, 1-19. [CrossRef]

7. Blomkvist, Y.; Ullemar Loenbom, L. Improving Supply Chain Visibility within Logistics by Implementing a Digital Twin: A Case Study at Scania Logistics; KTH Royal Institute of Technology: Stockholm, Sweden, 2020.

8. Tarli, M.; Masithah, S. The Effects of Supply Chain Visibility, Supply Chain Flexibility, Supplier Development and Inventory Control Toward Supply Chain Effectiveness. 2017. Available online: https:/ /ssrn.com/abstract=2984513 (accessed on 19 April 2021). 
9. Kot, S.; Haque, A.; Baloch, A. Supply chain management in smes: Global perspective. Montenegrin J. Econ. 2020, 16, 87-104. [CrossRef]

10. Lasi, H.; Fettke, P.D.P.; Kemper, H.-G.; Feld, D.-I.T.; Hoffmann, D.-H.M. Industry 4.0. Bus. Inf. Syst. Eng. 2014, 6, $239-242$. [CrossRef]

11. Tjahjono, B.; Esplugues, C.; Ares, E.; Pelaez, G. What does industry 4.0 mean to supply chain? Procedia Manuf. 2017, 13, 1175-1182. [CrossRef]

12. Birkel, H.; Müller, J.M. Potentials of industry 4.0 for supply chain management within the triple bottom line of sustainability-A systematic literature review. J. Clean. Prod. 2020, 289, 125612. [CrossRef]

13. Oláh, J.; Aburumman, N.; Popp, J.; Khan, M.A.; Haddad, H.; Kitukutha, N. Impact of Industry 4.0 on Environmental Sustainability. Sustainability 2020, 12, 4674. [CrossRef]

14. Moshood, T.D.; Adeleke, A.Q.; Nawanir, G.; Ajibike, W.A.; Shittu, R.A. Emerging Challenges and Sustainability of Industry 4.0 Era in the Malaysian Construction Industry. Emerg. Chall. Sustain. Ind. 2020, 4, 1627-1634.

15. Pfohl, H.-C.; Yahsi, B.; Kurnaz, T. The Impact of Industry 4.0 on the Supply Chain. In Innovations and Strategies for Logistics and Supply Chains: Technologies, Business Models and Risk Management. Proceedings of the Hamburg International Conference of Logistics (HICL); Hamburg University of Technology (TUHH): Hamburg, Germany, 2015; pp. 31-58.

16. Erboz, G. How to define industry 4.0: Main pillars of industry 4.0. Manag. Trends Dev. Enterp. Glob. Era 2017, 1, 761-767.

17. Uhlemann, T.H.-J.; Lehmann, C.; Steinhilper, R. The digital twin: Realizing the cyber-physical production system for industry 4.0. Procedia CIRP 2017, 61, 335-340. [CrossRef]

18. Negri, E.; Fumagalli, L.; Macchi, M. A review of the roles of Digital Twins in CPS-based production systems. Procedia Manuf. 2017, 11, 939-948. [CrossRef]

19. Tranfield, D.; Denyer, D.; Smart, P. Towards a Methodology for Developing Evidence-Informed Management Knowledge by Means of Systematic Review. Br. J. Manag. 2003, 14, 207-222. [CrossRef]

20. Briner, R.B.; Denyer, D. Systematic Review and Evidence Synthesis as a Practice and Scholarship Tool. In The Oxford Handbook of Evidence-Based Management; Oxford University Press: New York, NY, USA, 2012; pp. 112-129.

21. Webster, J.; Watson, R.T. Analyzing the past to prepare for the future: Writing a literature review. MIS Q. 2002, 26, xiii-xxiii.

22. Moshood, T.; Adeleke, A.; Nawanir, G.; Mahmud, F. Ranking of human factors affecting contractors' risk attitudes in the Malaysian construction industry. Soc. Sci. Humanit. Open 2020, 2, 100064. [CrossRef]

23. Rousseau, D.M.; Manning, J.; Denyer, D. Evidence in Management and Organizational Science: Assembling the Field's Full Weight of Scientific Knowledge through Syntheses. Acad. Manag. Ann. 2008, 2, 475-515. [CrossRef]

24. Watson, R.T. Beyond being Systematic in Literature Reviews in IS. J. Inf. Technol. 2015, 30, 185-187. [CrossRef]

25. Durach, C.F.; Kembro, J.; Wieland, A. A New Paradigm for Systematic Literature Reviews in Supply Chain Management. J. Supply Chain Manag. 2017, 53, 67-85. [CrossRef]

26. Kitchenham, B. Procedures for performing systematic reviews. Keele Univ. J. 2004, 33, 1-26.

27. Bastas, A.; Liyanage, K. Sustainable supply chain quality management: A systematic review. J. Clean. Prod. 2018, 181, 726-744. [CrossRef]

28. Thornhill, A.; Saunders, M.; Lewis, P. Research Methods for Business Students; Essex Pearson Education Ltd: Harlow, Essex, UK, 2009.

29. Rajeev, A.; Pati, R.K.; Padhi, S.S.; Govindan, K. Evolution of sustainability in supply chain management: A literature review. J. Clean. Prod. 2017, 162, 299-314. [CrossRef]

30. Paulus, T.M.; Bennett, A.M. I have a love-hate relationship with ATLAS.ti ${ }^{\text {TM}: ~ I n t e g r a t i n g ~ q u a l i t a t i v e ~ d a t a ~ a n a l y s i s ~ s o f t w a r e ~ i n t o ~ a ~}$ graduate research methods course. Int. J. Res. Method Educ. 2017, 40, 19-35. [CrossRef]

31. Moshood, T.D.; Nawanir, G.; Sorooshian, S.; Mahmud, F.; Adeleke, A.Q. Barriers and benefits of ICT adoption in the nigerian construction industry. a comprehensive literature review. Appl. Syst. Innov. 2020, 3, 46. [CrossRef]

32. Moshood, T.D.; Shittu, R.A.; Abidin, T. Covid-19 and 5G radiation are two parallel lines: A systematic review. Int. J. Innov. Sci. Res. Technol. 2020, 5, 744-751. [CrossRef]

33. Chang, Y.-T.; Hsieh, S.-H. A review of building information modeling research for green building design through building performance analysis. J. Inf. Technol. Constr. 2020, 25, 1-40. [CrossRef]

34. Shamseer, L.; Moher, D.; Clarke, M.; Ghersi, D.; Liberati, A.; Petticrew, M.; Shekelle, P.; Stewart, L.A.; PRISMA-P Group. Preferred reporting items for systematic review and meta-analysis protocols (PRISMA-P) 2015: Elaboration and explanation. BMJ 2015, 349, 1-25. [CrossRef]

35. Lu, W.; Yuan, H. A framework for understanding waste management studies in construction. Waste Manag. 2011, 31, 1252-1260. [CrossRef]

36. Friese, S.; Soratto, J.; Pires, D. Carrying out A Computer-Aided Thematic Content Analysis with ATLAS.ti. 2018. (18-02). Available online: http:/ /hdl.handle.net/21.11116/0000-0001-364E-C (accessed on 19 April 2021).

37. Friese, S.; Soratto, J.; Pires, D. Thematic content analysis using ATLAS.ti software: Potentialities for health research. Rev. Bras. Enferm. 2020, 73, e20190250.

38. Dolgui, A.; Ivanov, D.; Sokolov, B. Reconfigurable supply chain: The X-network. Int. J. Prod. Res. 2020, 58, 4138-4163. [CrossRef] 
39. Srai, J.S.; Settanni, E.; Tsolakis, N.; Aulakh, P.K. Supply chain digital twins: Opportunities and challenges beyond the hype. In Proceedings of the 23rd Cambridge International Manufacturing Symposium University of Cambridge, Cambridge, UK, 26-27 September 2019.

40. Grieves, M.; Vickers, J. Digital twin: Mitigating Unpredictable, Undesirable Emergent Behaviour in Complex Systems. In Transdisciplinary Perspectives on Complex Systems; Springer: Berlin/Heidelberg, Germany, 2017; pp. 85-113.

41. Tao, F.; Zhang, H.; Liu, A.; Nee, A.Y.C. Digital Twin in Industry: State-of-the-Art. IEEE Trans. Ind. Inform. 2018, 15, 2405-2415. [CrossRef]

42. Li, Z.; Wu, H.; King, B.; Ben Miled, Z.; Wassick, J.; Tazelaar, J. On the Integration of Event-Based and Transaction-Based Architectures for Supply Chains. In Proceedings of the 2017 IEEE 37th International Conference on Distributed Computing Systems Workshops (ICDCSW), Atlanta, GA, USA, 5-8 June 2017; pp. 376-382.

43. Francis, V. Supply chain visibility: Lost in translation? Int. J. Supply Chain Manag. 2008, 13, 180-184. [CrossRef]

44. Swift, C.; Guide, V.D.R., Jr.; Muthulingam, S. Does supply chain visibility affect operating performance? Evidence from conflict minerals disclosures. J. Oper. Manag. 2019, 65, 406-429. [CrossRef]

45. Lohmer, J.; Bugert, N.; Lasch, R. Analysis of resilience strategies and ripple effect in blockchain-coordinated supply chains: An agent-based simulation study. Int. J. Prod. Econ. 2020, 228, 107882. [CrossRef]

46. Wei, H.-L.; Wang, E.T.G. The strategic value of supply chain visibility: Increasing the ability to reconfigure. Eur. J. Inf. Syst. 2010, 19, 238-249. [CrossRef]

47. Busse, C.; Schleper, M.C.; Weilenmann, J.; Wagner, S.M. Extending the supply chain visibility boundary: Utilizing stakeholders for identifying supply chain sustainability risks. Int. J. Phys. Distrib. Logist. Manag. 2017. [CrossRef]

48. Supply Chain Control Tower Visuals (Page 2)-Line.17QQ.com. Available online: https:/ /line.17qq.com/articles/wwkffkwy_p2 .html (accessed on 19 April 2021).

49. Barratt, M.; Oke, A. Antecedents of supply chain visibility in retail supply chains: A resource-based theory perspective. J. Oper. Manag. 2007, 25, 1217-1233. [CrossRef]

50. Kiss, K.; Ruszaki, C.; Szúcs, A.; Koncz, G. Examining the Role of Local Products in Rural Development in the Light of Consumer Preferences-Results of a Consumer Survey from Hungary. Sustainability 2020, 12, 5473. [CrossRef]

51. Mirabelli, G.; Solina, V. Blockchain and agricultural supply chains traceability: Research trends and future challenges. Procedia Manuf. 2020, 42, 414-421. [CrossRef]

52. Wang, E.T.G.; Wei, H.-L. Interorganizational Governance Value Creation: Coordinating for Information Visibility and Flexibility in Supply Chains. Decis. Sci. 2007, 38, 647-674. [CrossRef]

53. Kimseng, T.; Javed, A.; Jeenanunta, C.; Kohda, Y. Sustaining Innovation through Joining Global Supply Chain Networks: The Case of Manufacturing Firms in Thailand. Sustainability 2020, 12, 5259. [CrossRef]

54. Christidis, K.; Devetsikiotis, M. Blockchains and Smart Contracts for the Internet of Things. IEEE Access 2016, 4, $2292-2303$. [CrossRef]

55. Teece, D.J. Explicating dynamic capabilities: The nature and microfoundations of (sustainable) enterprise performance. Strat. Manag. J. 2007, 28, 1319-1350. [CrossRef]

56. Zollo, M.; Winter, S.G. Deliberate Learning and the Evolution of Dynamic Capabilities. Organ. Sci. 2002, 13, 339-351. [CrossRef]

57. Simatupang, T.M.; Sridharan, R. A benchmarking scheme for supply chain collaboration. Benchmarking Int. J. 2004, 11, 9-30. [CrossRef]

58. Kraft, T.; Valdés, L.; Zheng, Y. Supply chain visibility and social responsibility: Investigating consumers' behaviours and motives. Manuf. Serv. Oper. Manag. 2018, 20, 617-636. [CrossRef]

59. Somapa, S.; Cools, M.; Dullaert, W. Characterizing supply chain visibility-A literature review. Int. J. Logist. Manag. 2018. [CrossRef]

60. Dubey, R.; Gunasekaran, A.; Childe, S.J.; Papadopoulos, T.; Luo, Z.; Roubaud, D. Upstream supply chain visibility and complexity effect on focal company's sustainable performance: Indian manufacturers' perspective. Ann. Oper. Res. 2020, 290, 343-367. [CrossRef]

61. Gosain, S.; Malhotra, A.; El Sawy, O.A. Coordinating for Flexibility in e-Business Supply Chains. J. Manag. Inf. Syst. 2004, 21, 7-45. [CrossRef]

62. Silva, N.; Ferreira, L.M.D.; Silva, C.; Magalhães, V.; Neto, P. Improving Supply Chain Visibility With Artificial Neural Networks. Procedia Manuf. 2017, 11, 2083-2090. [CrossRef]

63. Elgarah, W.; Falaleeva, N.; Saunders, C.C.; Ilie, V.; Shim, J.T.; Courtney, J.F. Data Exchange in Inter-Organizational Relationships: A Review through Multiple Conceptual Lenses. In Data Base for Advances in Information Systems; ACM SIGMIS Database; Association for Computing Machinery: New York, NY, USA, 2005; pp. 8-29.

64. Grieves, M. Digital twin: Manufacturing excellence through virtual factory replication. White Pap. 2014, 1, 1-7.

65. Lu, Y.; Liu, C.; Wang, K.I.-K.; Huang, H.; Xu, X. Digital Twin-driven smart manufacturing: Connotation, reference model, applications and research issues. Robot. Comput. Integr. Manuf. 2020, 61, 101837. [CrossRef]

66. Qi, Q.; Tao, F.; Zuo, Y.; Zhao, D. Digital twin service towards smart manufacturing. Procedia CIRP 2018, 72, 237-242. [CrossRef]

67. How Digital Twin and Analytics Improve Operations, Minimize Costs I Jacobs. Available online: https://www.jacobs.com/ projects/replica-digital-twin (accessed on 19 April 2021). 
68. Mandal, S. The influence of dynamic capabilities on hospital-supplier collaboration and hospital supply chain performance. Int. J. Oper. Prod. Manag. 2017, 37, 664-684. [CrossRef]

69. Tozanl1, Ö.; Kongar, E.; Gupta, S. Evaluation of Waste Electronic Product Trade-in Strategies in Predictive Twin Disassembly Systems in the Era of Blockchain. Sustainability 2020, 12, 5416. [CrossRef]

70. Srinivasan, R.; Swink, M. An Investigation of Visibility and Flexibility as Complements to Supply Chain Analytics: An Organizational Information Processing Theory Perspective. Prod. Oper. Manag. 2018, 27, 1849-1867. [CrossRef]

71. Ivanov, D.; Dolgui, A.; Das, A.; Sokolov, B. Digital Supply Chain Twins: Managing the Ripple Effect, Resilience, and Disruption Risks by Data-Driven Optimization, Simulation, and Visibility. In Handbook of Ripple Effects in the Supply Chain; Springer: Berlin/Heidelberg, Germany, 2019; pp. 309-332.

72. Fan, C.; Zhang, C.; Yahja, A.; Mostafavi, A. Disaster CityDigital Twins: A vision for integrating artificial and human intelligence for disaster management. Int. J. Inf. Manag. 2021, 56, 102049. [CrossRef]

73. Wang, J.; Ye, L.; Gao, R.X.; Li, C.; Zhang, L. Digital Twin for rotating machinery fault diagnosis in smart manufacturing. Int. J. Prod. Res. 2019, 57, 3920-3934. [CrossRef]

74. Fan, C.; Jiang, Y.; Mostafavi, A. Social Sensing in Disaster City Digital Twin: Integrated Textual-Visual-Geo Framework for Situational Awareness during Built Environment Disruptions. J. Manag. Eng. 2020, 36, 04020002. [CrossRef]

75. Shahat, E.; Hyun, C.T.; Yeom, C. City digital twin potentials: A review and research agenda. Sustainability 2021, $13,3386$. [CrossRef]

76. Xu, Y.; Sun, Y.; Liu, X.; Zheng, Y. A Digital-Twin-Assisted Fault Diagnosis Using Deep Transfer Learning. IEEE Access 2019, 7, 19990-19999. [CrossRef]

77. Elmo, D.; Stead, D. Disrupting rock engineering concepts: Is there such a thing as a rock mass digital twin and are machines capable of learning rock mechanics? In Proceedings of the 2020 International Symposium on Slope Stability in Open Pit Mining and Civil Engineering, Perth, WA, Australia, 12-14 May 2020; pp. 565-576.

78. Wang, P.; Luo, M. A digital twin-based big data virtual and real fusion learning reference framework supported by industrial internet towards smart manufacturing. J. Manuf. Syst. 2021, 58, 16-32. [CrossRef]

79. Franciosa, P.; Sokolov, M.; Sinha, S.; Sun, T.; Ceglarek, D. Deep learning enhanced digital twin for Closed-Loop In-Process quality improvement. CIRP Ann. 2020, 69, 369-372. [CrossRef]

80. Wanasinghe, T.R.; Wroblewski, L.; Petersen, B.; Gosine, R.G.; James, L.A.; De Silva, O.; Mann, G.K.I.; Warrian, P.J. Digital twin for the oil and gas industry: Overview, research trends, opportunities, and challenges. IEEE Access 2020, 8, 104175-104197. [CrossRef]

81. Barricelli, B.R.; Casiraghi, E.; Gliozzo, J.; Petrini, A.; Valtolina, S. Human Digital Twins for fitness management. IEEE Access 2020, 8, 26637-26664. [CrossRef]

82. Park, K.T.; Son, Y.H.; Noh, S.D. The architectural framework of a cyber physical logistics system for digital-twin-based supply chain control. Int. J. Prod. Res. 2020, 1-22. [CrossRef]

83. Guo, D.; Zhong, R.Y.; Lin, P.; Lyu, Z.; Rong, Y.; Huang, G.Q. Digital twin-enabled Graduation Intelligent Manufacturing System for fixed-position assembly islands. Robot. Comput. Integr. Manuf. 2020, 63, 101917. [CrossRef]

84. Jordan, M.I.; Mitchell, T.M. Machine learning: Trends, perspectives, and prospects. Science 2015, 349, 255-260. [CrossRef] [PubMed]

85. Camerer, C.F. Artificial Intelligence and Behavioural Economics. In The Economics of Artificial Intelligence: An Agenda; University of Chicago Press: Chicago, IL, USA, 2018; pp. 587-608.

86. Xia, F.; Yang, L.T.; Wang, L.; Vinel, A. Internet of Things. Int. J. Commun. Syst. 2012, 25, 1101-1102. [CrossRef]

87. Ben-Daya, M.; Hassini, E.; Bahroun, Z. Internet of Things and supply chain management: A literature review. Int. J. Prod. Res. 2019, 57, 4719-4742. [CrossRef]

88. Haße, H.; Li, B.; Weißenberg, N.; Cirullies, J.; Otto, B. Digital Twin for Real-Time Data Processing in Logistics. In Artificial Intelligence and Digital Transformation in Supply Chain Management: Innovative Approaches for Supply Chains. Proceedings of the Hamburg International Conference of Logistics (HICL); Technische Universität Hamburg: Hamburg, Germany, 2019 ; pp. 4-28.

89. Arora, R.; Parashar, A. Secure user data in cloud computing using encryption algorithms. Int. J. Eng. Res. Appl. 2013, 3, 1922-1926.

90. Jung, T.; tom Dieck, M.C. Augmented Reality and Virtual Reality; Springer: Berlin/Heidelberg, Germany, 2018.

91. Olshannikova, E.; Ometov, A.; Koucheryavy, Y.; Olsson, T. Visualizing Big Data with augmented and virtual reality: Challenges and research agenda. J. Big Data 2015, 2, 1-27. [CrossRef]

92. Ge, X.; Pan, L.; Li, Q.; Mao, G.; Tu, S. Multipath Cooperative Communications Networks for Augmented and Virtual Reality Transmission. IEEE Trans. Multimed. 2017, 19, 2345-2358. [CrossRef]

93. Yang, C.-S. Maritime shipping digitalization: Blockchain-based technology applications, future improvements, and intention to use. Transp. Res. Part E Logist. Transp. Rev. 2019, 131, 108-117. [CrossRef]

94. Omollo, C.A. Disruptive Technologies in the Logistics And Supply Chain Industry: A Study on Blockchain; United States International University Africa: Nairobi, Kenya, 2019.

95. Conrad, E.; Misenar, S.; Feldman, J. Domain 8: Software Development Security (Understanding, Applying, and Enforcing Software Security). In CISSP Study Guide, 3rd ed.; Syngress: Boston, MA, USA, 2016; pp. 429-477.

96. Modoni, G.E.; Caldarola, E.G.; Sacco, M.; Terkaj, W. Synchronizing physical and digital factory: Benefits and technical challenges. Procedia CIRP 2019, 79, 472-477. [CrossRef] 
97. Kritzinger, W.; Karner, M.; Traar, G.; Henjes, J.; Sihn, W. Digital Twin in manufacturing: A categorical literature review and classification. IFAC-PapersOnLine 2018, 51, 1016-1022. [CrossRef]

98. Loup, R.; Koller, R. The road to commitment: Capturing the head, hearts and hands of people to effect change. Organ. Dev. J. 2005, 23, 73-81.

99. Samir, K.; Maffei, A.; Onori, M.A. Real-Time asset tracking: A starting point for Digital Twin implementation in Manufacturing. Procedia CIRP 2019, 81, 719-723. [CrossRef]

100. Phelps, L.W.; Ackerman, J.M. Making a case for disciplinarity in rhetoric, composition, and writing studies: The visibility project. Coll. Compos. Commun. 2010, 60, 180-215.

101. Rasheed, O.S.; Kvamsdal, T. Digital twin: Values, challenges and enablers. arXiv 2019, arXiv:1910.01719.

102. Ham, Y.; Kim, J. Participatory sensing and digital twin city: Updating virtual city models for enhanced risk-informed decisionmaking. J. Manag. Eng. 2020, 36, 4020005. [CrossRef]

103. Miri, S. Digital Twin for Hybrid Installations. Maste's Thesis, Tampere University, Tampere, Finland, 2018. Available online: http:/ / urn.fi/URN:NBN:fi:tty-201809122285 (accessed on 3 October 2020).

104. Orozco-Romero, A.; Arias Portela, C.; Marmolejo, J.A. The Use of Agent-Based Models Boosted by Digital Twins in the Supply Chain: A Literature Review. In Proceedings of the 2nd International Conference on Intelligent Computing and Optimization (ICO 2019); Springer: Berlin/Heidelberg, Germany, 2019; pp. 642-652. 